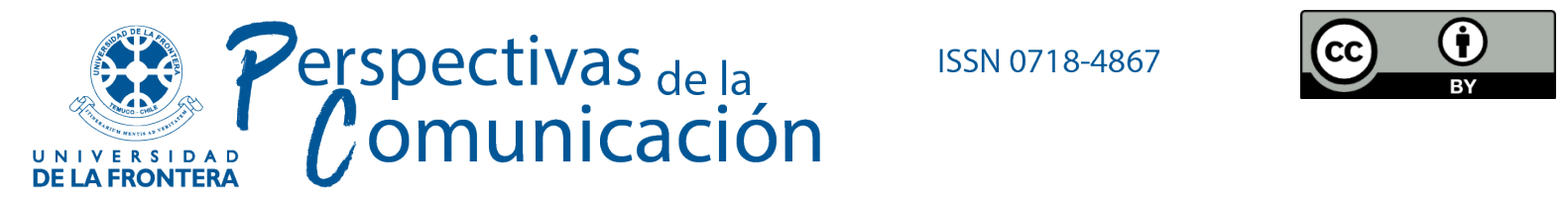

Artículo

\title{
¿MOTINES O ACCIONES COLECTIVAS DE RECLAMO? DISCURSOS MEDIÁTICOS DURANTE EL COVID-19 \\ SOBRE EL SISTEMA PENITENCIARIO PERUANO Y LAS PERSONAS RECLUIDAS
}

DOI: POR ASIGNAR

Dra. Lucia Bracco Bruce

Grupo de Investigación en Psicología Forense y Penitenciaria, Pontificia Universidad Católica del Perú, Lima, Perú lucia.bracco@pucp.pe

ORCID iD: https://orcid.org/o0oo-0003-0163-5625

Mg. Adriana Hildenbrand Mellet

Grupo de Investigación en Psicología Forense y Penitenciaria, Pontificia Universidad Católica del Perú, Lima, Perú adriana.hildenbrand@pucp.pe

ORCID iD: https://orcid.org/oooo-0001-5015-1809

Lic. Ana Sofía Carranza Risco

Grupo de Investigación en Psicología Forense y Penitenciaria, Pontificia Universidad Católica del Perú, Lima, Perú carranza.as@pucp.edu.pe

ORCID iD: https://orcid.org/o000-0002-1073-4492

Lic. Valeria Lindley Llanos

Grupo de Investigación en Psicología Forense y Penitenciaria, Pontificia Universidad Católica del Perú, Lima, Perú valeria.lindley@pucp.edu.pe

ORCID iD: https://orcid.org/oooo-0002-1901-2365

Recibido el 2020-10-27

Revisado el 2021-05-03

Aceptado el 2021-06-07

Publicado el 2021-07-12 


\section{Resumen}

Los medios de comunicación masiva tienen un rol protagónico en la construcción de símbolos, valores y prácticas sociales. Con la finalidad de identificar la imagen que se transmite sobre el sistema penitenciario y las personas recluidas, el artículo analiza los discursos de la prensa peruana escrita en plataformas digitales acerca de las acciones colectivas de reclamo (nombradas como motines) en el marco de la COVID-19. Se realiza un análisis crítico del discurso del texto escrito de 81 notas periodísticas de los siete diarios más leídos en el Perú sobre las primeras acciones colectivas de reclamo que ocurrieron en cuatro establecimientos penitenciarios: Río Seco, Picsi, Castro Castro y Anexo Chorrillos. Se discuten tres ejes: (a) Explicación de los diarios acerca de las acciones colectivas de reclamo; (b) Los establecimientos penitenciarios para hombres: acciones colectivas de reclamo definidas como motín; y (c) Los establecimientos penitenciarios para mujeres: acciones colectivas de reclamo definidas como no-motín. Las notas periodísticas reproducen la imagen de la cárcel como institución de castigo, con una tendencia a deslegitimar las acciones colectivas y a mostrar a las personas recluidas como sujetos impulsados por la emoción y sin posibilidad de dialogar, lo que justifica la lógica de control. Además, los discursos se encuentran atravesados por estereotipos de criminalidad y género. Se informa a partir de la simplificación de la realidad penitenciaria con imágenes unidimensionales de los establecimientos penitenciarios y las personas recluidas. Esto dificulta construir miradas holísticas, entender procesos de vulneración y reclamo de derechos de las personas recluidas y entablar procesos de diálogo para construir resoluciones alternativas a la violencia.

Palabras clave: centros penitenciarios, movilización social, derechos humanos, análisis de discurso, medios de comunicación, contenidos digitales. 


\title{
RIOTS OR COLLECTIVE CLAIM ACTIONS? PRESS DISCOURSES DURING COVID-19 ABOUT PERUVIAN PRISONS AND PRISONERS
}

\begin{abstract}
Mass Media has a leading role in the construction of social symbols, values and practices. To identify the images of prisoners and prisons, in this article, we focus on the discourses of the Peruvian written press about the collective actions (categorized as riots) of prisoners in the context of COVID-19. Through critical discourse analysis, we analyze 81 notes of the seven most-read journals in Peru which inform about the first collective claim actions that occurred in four prisons: Río Seco, Picsi, Castro Castro and Anexo Chorrillos. The results are organized into three axes: (a) Explanation of the diaries about collective claim action; (b) Men's prisons: Collective claim action defined as riots; and (c) Women's prisons: Collective claim action defined as non-riots. We argue that the notes reproduce the image of prison as a punishment institution, with a tendency to delegitimize collective actions and to portray prisoners as subjects propelled by emotions with no possibility to establish a dialogical encounter. Also, discourses are embedded with stereotypes of crime and gender. Mass media informs through the simplification of the prison system, providing unidimensional images of prisons and prisoners. This makes it difficult to create holistic views that aid to understand the hindering and claims for prisoners' rights in order to establish processes of dialogue to construct alternative resolutions to violence.
\end{abstract}

Keywords: prisons, social mobilization, human rights, discourse analysis, mass media, digital contents. 
Perspectivas de la Comunicación

Página 172

Universidad de La Frontera

ISSN 0718-4867

www.perspectivasdelacomunicacion.cl 


\section{Introducción}

Los Medios de Comunicación Masiva (MCM) tienen un papel protagónico en la construcción y difusión de discursos acerca de la desviación, la criminalidad, los establecimientos penitenciarios y las lógicas de castigo y represión de las personas que transgreden las leyes. Con la finalidad de identificar la imagen que se transmite sobre el sistema penitenciario y las personas recluidas en él, este artículo analiza cómo los MCM peruanos, específicamente la prensa escrita en plataformas digitales, informan sobre las acciones denominadas protestas o motines que ocurrieron en los establecimientos penitenciarios del Perú en el marco de la emergencia sanitaria de la pandemia de COVID-19. A lo largo de este documento, nos referiremos a estos eventos como Acciones Colectivas de Reclamo (ACR), ${ }^{1}$ definiéndose como el movimiento de un grupo de personas que actúan en colectividad para denunciar una situación que debe ser transformada; en este caso, la gestión de la prevención y atención durante la emergencia sanitaria de la COVID-19 por parte de las autoridades penitenciarias.

Estudiar las ACR y su cobertura mediática en el marco de la pandemia cobra particular importancia, pues los pedidos de la población intramuros coinciden con preocupaciones de la población extramuros: implementación de medidas de prevención eficaces y acceso a respuesta en caso de contagio. A través de estos discursos es posible observar qué grupos son incluidos o excluidos en el reclamo por el acceso al derecho inalienable a la salud. Al mismo tiempo, el marco de emergencia generó una particular simultaneidad de ACR en distintos establecimientos penitenciarios dando una mirada amplia del fenómeno, cuya representación mediática superó la cobertura usual. Si bien los MCM informan sobre hechos específicos, también permiten observar cuál es la mirada del sistema penitenciario (el cual se encuentra en constante situación de crisis) y cómo eventos macrosociales cambiantes como la COVID-19, brindan aún más exposición a sus deficiencias y precariedad estructural. De esta manera, el análisis de las ACR durante la emergencia sanitaria se encuentra enmarcado en un contexto particular, pero su pertinencia reside en que nos

1 En la redacción de este artículo, como autoras nos vimos cuestionadas por el lenguaje a utilizar sobre los hechos a analizar. De manera general, se tiende a utilizar indistintamente las palabras motín, manifestación, protesta o reclamo. Nos encontramos con palabras que, como veremos, están cargadas de significados y que marcan, a su vez, una postura sobre cómo se perciben estos actos y las personas que los llevan a cabo. Por ello, decidimos utilizar el término "acciones colectivas" que, si bien no está libre de ideología, supone un carácter más descriptivo.

Perspectivas de la Comunicación - Vol. 14 - No 1 - 2021 - pp. 169-203

Universidad de la Frontera - Chile 
muestra problemáticas estructurales en el funcionamiento del sistema penitenciario y una constante búsqueda del ejercicio de sus derechos por parte de las personas privadas de libertad.

Los establecimientos penitenciarios son entendidos como espacios cerrados y aislados de la sociedad que tienen la finalidad de castigar, controlar y disciplinar a sujetos que han transgredido la ley para convertirlos en ciudadanos productivos (Goffman, 1961; Foucault, 1975; Melossi \& Pavarini, 2017). Sostenemos que los establecimientos penitenciarios son espacios de mortificación (Jewkes, 2002), es decir, de dolor, sufrimiento y límite a la autonomía de las personas recluidas, que se convierten en una suerte de castigo sobre el castigo. Dentro de esta situación punitiva, las personas recluidas no se encuentran completamente desprovistas de poder, sino que realizan acciones para mejorar sus condiciones de vida durante el encarcelamiento, entre las cuales está el reclamo frente a situaciones de injusticia o vulneración de derechos.

Además de la mortificación que puede producir el encierro en sí, en Latinoamérica se suma que los establecimientos penitenciarios son espacios hostiles e insalubres, sumergidos en una situación estructural de hacinamiento y condiciones inhumanas de habitabilidad (Bergman, 2020). Todo ello confluye para que las cárceles sean potenciales epicentros de enfermedades infecciosas, conllevando a que las personas recluidas se encuentren en mayor riesgo que comunidades extramuros (Nowonty \& Piquero, 2020; Pyrooz et al., 2020). Así, la COVID-19 tuvo una alta propagación en los sistemas penitenciarios de la región (Centro de Estudios Latinoamericanos sobre Inseguridad y Violencia [CELIV], 2020).

A pesar del deber estatal de no discriminar por situación legal al garantizar el acceso a los servicios de salud, y del compromiso durante la pandemia de proteger a las poblaciones en mayor vulnerabilidad (Corte Interamericana de Derechos Humanos [CIDH], 2020), las respuestas médicas durante la emergencia sanitaria en los establecimientos penitenciarios latinoamericanos fueron lentas e ineficientes (CELIV, 2020). Ante ello, más de la mitad de los sistemas penitenciarios de la región reportó ACR entre los meses de marzo y mayo de 2020 (CELIV, 2020). En el Perú, si bien se realizaron actividades preventivas organizadas por las personas recluidas (Instituto Nacional Penitenciario del Perú [INPE], 2020), la cobertura mediática se enfocó en las ACR, mostrándolas como actos de insubordinación y enfatizando la violencia de las personas recluidas. 
Tomando en cuenta lo anterior, consideramos que los MCM son reproductores de discursos hegemónicos y espacio de disputa de intereses (Varona, 2011), pero también una fuente de análisis de la realidad social. Para profundizar en el análisis, precisamos primero los enfoques teóricos utilizados sobre los establecimientos penitenciarios y los MCM.

\subsection{La cárcel, su relación con el poder y las acciones colectivas/motines}

Las cárceles son lugares de disputa de poder. Por un lado, Goffman (1961) acuñó el concepto de "institución total" para referirse a espacios de confinamiento con una organización burocrática que maneja las actividades de la población recluida, como ocurre en cárceles u hospitales mentales. Una característica central de estas instituciones es la fragmentación entre un grupo más grande de personas que viven dentro de ellas, con restringido contacto con el mundo externo (internos/as) y un grupo más pequeño que las supervisa (personal penitenciario). Esta separación propicia la construcción de un poder jerárquico donde coexisten grupos binarios y cerrados. Por otro lado, como sostienen investigadoras feministas, la cárcel también es definida como institución patriarcal que tiende a refeminizar a las mujeres recluidas a través de un discurso moralizador y a ejercer mayor control sobre ellas en comparación a sus pares hombres (Bex, 2016; Bosworth \& Kaufman, 2013; Guala, 2016). Así, la concentración del poder se ubicaría en quienes representan la institución formal como lo son las autoridades y el personal penitenciario, usándolo de manera diferenciada frente a población penitenciaria masculina o femenina.

Investigaciones recientes sobre establecimientos penitenciarios en Latinoamérica cuestionan esta conceptualización e invitan a repensar las dinámicas de poder y gobernanza en el sistema penitenciario. Se resalta que las cárceles en Latinoamérica son espacios de negociación, que funcionan a partir de la organización colectiva y participación de la población recluida, instaurando formas de auto o cogobierno. Esta perspectiva redefine las luchas de poder entre personal penitenciario y personas recluidas desde la concepción de la prisión como una institución permeable, donde el poder es multidireccional y las relaciones interpersonales son más fluidas y flexibles (Bracco, 2021; Cunha, 2014; Darke \& Garcés, 2017; Veeken, 2000).

Si bien estas formas de funcionamiento, en mayor o menor medida, prevalecen en la práctica cotidiana de establecimientos penitenciarios latinoamericanos, el imaginario colectivo hegemónico sobre cómo deberían funcionar las instituciones penitenciarias continúa asociado a la definición clásica de Goffman. De manera generalizada, los centros 
penitenciarios se interpretan como sistemas verticales donde la autoridad carcelaria concentra el control y el poder, disputados ilegítimamente por las personas privadas de libertad (Useem, 2018). Al respecto, si bien la criminología como corpus teórico se construye desde un sistema patriarcal (Renzetti, 2018) y hay menos investigaciones sobre la población penitenciaria femenina, esta interpretación se reproduce y acentúa en el caso de las cárceles de mujeres.

Considerando el paradigma del poder como unidireccional y gestado desde la autoridad carcelaria, se tiende a estudiar las ACR en establecimientos penitenciarios como motines: movimientos colectivos donde las personas recluidas, mayormente varones, enfrentan a la autoridad, resultando lícito el uso de la fuerza para impedir agresiones o fugas (Cabanellas, 2012; Easton, 2018). Otras miradas interpretan los motines como señales de alerta de un sistema en crisis, ya sea por condiciones precarias, insuficiente personal y/o recursos, o cuestionamiento de la legitimidad de la institución, por ejemplo, ante percepción de injusticias o manejo inadecuado de cambios repentinos (Easton, 2018; Useem, 2018). En esa línea, los motines se explican desde aspectos circunstanciales y estructurales del encierro, en diálogo con la agencia de las personas involucradas (personas recluidas, agentes penitenciarios/as, áreas administrativas, etc.) (Carrabine, 2005).

Frente a ello, un liderazgo institucional efectivo supondría escuchar a los actores involucrados y desarrollar estrategias consecuentes para responder a las bases del conflicto (Useem, 2018). Sin embargo, dado el estatus legal de las ACR dentro de los establecimientos penitenciarios, frecuentemente se corre el riesgo de que la resolución no sea necesariamente pacífica y que los derechos que constitucionalmente protegen a la población nacional queden fuera de los muros (Desta, 2019). Partir del paradigma de la institución total con legítima centralización del poder, parece justificar la vulneración de derechos como la libertad de expresión y el derecho a denunciar (Alto Comisionado de las Naciones Unidas para los Derechos Humanos, 2014; CIDH, 2008).

\subsection{Los MCM en la construcción de imaginarios colectivos sobre delincuencia y encarcelamiento}

Históricamente, la desviación de la ley y su control han formado parte de los MCM; y en las últimas décadas se identifica un incremento particular en la cobertura de delitos violentos (Greer \& Reiner, 2012). Las representaciones mediáticas son los principales canales de la población civil para acceder a discursos sobre crimen y justicia (Easton, 2018; Schlesinger, Tumber \& Murdock, 1991) y, al mismo tiempo, tienen un impacto en la forma en que las 
personas privadas de su libertad definen sus identidades (Jewkes, 2002). Por ello, resulta indispensable profundizar en la posición que adoptan los MCM al abordar procesos sociales y políticos vinculados al ámbito penitenciario (Kidd-Hewitt, 1995; Mathiesen, 1997; Varona, 2011). Especialmente en la aproximación a la cárcel, institución simultáneamente protagónica y escondida de la sociedad, los MCM se ubican en un lugar privilegiado para la construcción social de los imaginarios acerca de la criminalidad y la población recluida.

A través de texto escrito y contenido audiovisual, los discursos mediáticos se plasman como actos sociales construidos desde intereses ideológicos, develando una tendencia a la reproducción de ideologías dominantes (Greer \& Reiner, 2012; Mengo, 2004; Dijk, 2018). Adicionalmente, sin negar la posibilidad de lectoría crítica, cabe resaltar la posición de poder de los MCM frente a otros géneros discursivos. Como sostiene Teun van Dijk (2017), los MCM influyen en los modelos mentales de su público, ya que representan una fuente de opinión e interpretación de fenómenos sociales. Posición que adquieren, en parte, a través de la expectativa de veracidad en sus postulados, y amplifica su efecto en los modelos mentales del público, envolviéndolo en la lógica que proponen (Mengo, 2004).

Distintos autores abordan las formas en que los MCM refieren a grupos minoritarios o marginados desde estereotipos simplificantes (entre otros, Kidd-Hewitt, 1995; Moreno, 2016; Schlesinger, Tumber \& Murdock, 1991; Dijk, 2018). En el caso de la delincuencia, esta suele caracterizarse como producto de decisiones individuales y maldad aislada, distrayendo la atención del papel de la estructura social y la cultura (Greer \& Reiner, 2012). Al mismo tiempo, Cohen (2002) sostiene que la sociedad cataloga a las personas que quiebran las reglas como grupos desviados y que, una vez puestos en dicha etiqueta, sus actos serán interpretados bajo ese estatus.

Frente a ello, los MCM se posicionan como "emprendedores morales" (Cohen, 2002, p. 10) que establecen los límites entre lo correcto y lo incorrecto, con un rol determinante en qué constituye una noticia y cómo se informa sobre comportamientos del grupo "desviado". Desde este punto, el autor propone que la alta presencia mediática de comportamientos desviados y sus consecuencias puede generar indignación o pánico en el público, moldear comportamientos sociales y generar una ruta en espiral al etiquetar a un grupo como desviado: se llama la atención sobre una transgresión al reportarla, se informa respuesta punitiva, el grupo es segregado, se le etiqueta como aún más desviado y se aplica aún más punición. 
A través de esta lente, la sociedad se convierte en lo que Mathiesen (1997) denomina "a viewer society [una sociedad espectadora]" (p. 219), donde una cultura de vigilancia se cimienta sobre el panóptico y el sinóptico. Desde el primero, trabajado por Bentham y Foucault, el control social se fortalece por sistemas basados en la observación de unos pocos sobre muchos, explicada previamente. El segundo resalta cómo los MCM amplían la posibilidad de que muchos vigilen a unos pocos y asuman un rol de contraparte. La recuperación del sinóptico como estructura moderna exige una aproximación integral que supere las noticias aisladas y aborde a profundidad los patrones y sus implicancias.

El sinóptico se erige dinámicamente entre los MCM y el público, donde ambas partes, de manera inter-relacional, construyen, reproducen y difunden discursos acerca de fenómenos como la criminalidad. En el caso peruano, resulta interesante que los/as lectores/as que interactúan con los $\mathrm{MCM}$ en plataformas digitales tienen un perfil demográfico determinado: urbano, adultez joven y con cierto poder adquisitivo (Instituto Nacional de Estadística e Informática, 2020). A ello se suman las concepciones sobre la (in)seguridad ciudadana: una encuesta del Instituto de Estudios Peruanos (2019) muestra que 76 \% de peruanos/as reportó sentirse inseguro/a (cifra estable desde 2015) y que 50 \% reclama la implementación de sanciones más duras frente a esta problemática. En un contexto semejante, Varona (2011) identifica un posible efecto de la reproducción de discursos estereotipados en la presión social para el endurecimiento del castigo hacia la delincuencia. Así, en la reiteración de representaciones de amenaza, los medios abren el camino para el control como medicina social (Greer \& Reiner, 2012).

Tomando en cuenta lo presentado, en este artículo se busca analizar las formas en que los MCM escritos en plataformas digitales y difundidos a nivel nacional, informan sobre las ACR dentro de los establecimientos penitenciarios del Perú, en el marco de la emergencia sanitaria por COVID-19. De manera más específica, se pretende: a) Identificar cómo se describen los hechos ocurridos en los establecimientos penitenciarios en las notas periodísticas, considerando cómo se nombran, qué hechos se enfatizan y cuáles se invisibilizan; b) Explorar cuáles son las principales explicaciones que las notas periodísticas brindan sobre lo ocurrido dentro de los establecimientos penitenciarios; c) Analizar cómo se caracteriza a las personas recluidas en las notas periodísticas; y d) Analizar semejanzas y diferencias en el reporte de ACR que ocurren en establecimientos penitenciarios para hombres y mujeres. 


\section{Método}

\subsection{Selección de corpus de análisis}

La selección de diarios peruanos a analizar siguió dos criterios: supera 200.000 lectores/as por día (Compañía Peruana de Estudios de Mercado, 2016) e incluye al menos una nota periodística sobre las ACR seleccionadas para el presente estudio. Así, son siete los MCM que cubren ambos criterios: Trome (TR), Ojo (OJ), El Popular (EP), Correo (CO), El Comercio (EC), Perú21 (PE) y La República (LR).

Cabe resaltar que en el Perú existe un oligopolio comunicacional: cinco de los diarios analizados pertenecen al Grupo El Comercio, y los otros dos, al Grupo La República (Media Ownership Monitor Perú, 2020). Señalamos este hecho pues podría influir en una mirada homogénea sobre cómo se informan las ACR, que se analizará en la discusión.

El corpus de análisis son las notas periodísticas en plataforma digital que informan sobre las ACR que ocurrieron en cuatro establecimientos penitenciarios peruanos durante los primeros meses de la emergencia sanitaria por COVID-19, entre marzo y mayo del 2020: el Establecimiento Penitenciario Piura, conocido como Río Seco, y el Establecimiento Penitenciario Chiclayo, conocido como Picsi, ambos ubicados en la región norte del país; Establecimiento Penitenciario Miguel Castro Castro y Establecimiento Penitenciario Anexo Mujeres Chorrillos, ambos ubicados en Lima (tabla 1). Nos centramos en la primera acción cubierta por los MCM en cada establecimiento a fin de delimitar la aproximación metodológica. Sin embargo, en algunos, las acciones se extendieron por varias semanas. 
Tabla 1. Cobertura mediática de las acciones colectivas en prisiones seleccionadas para el presente análisis.

\begin{tabular}{|c|c|c|}
\hline $\begin{array}{l}\text { Establecimiento } \\
\text { Penitenciario } \\
\text { Ciudad, fecha* }\end{array}$ & Descripción de la ACR & $\begin{array}{l}\text { Cobertura } \\
\text { mediática }\end{array}$ \\
\hline $\begin{array}{c}\text { Río Seco } \\
\text { Piura, 18.03.2020 }\end{array}$ & $\begin{array}{c}\text { Primera ACR en Perú vinculada a la COVID-19 } \\
\text { informada por MCM. Aún no existían reportes de } \\
\text { contagios dentro del establecimiento penitenciario. }\end{array}$ & $\begin{array}{c}14^{* *} \text { piezas } \\
\text { periodísticas }\end{array}$ \\
\hline $\begin{array}{l}\text { Picsi } \\
\text { Lambayeque, } \\
19.03 .2020\end{array}$ & $\begin{array}{l}\text { Casi en simultáneo con el evento anterior. A partir de } \\
\text { este evento, las expresiones de reclamo en este } \\
\text { establecimiento se extendieron durante cinco } \\
\text { semanas. }\end{array}$ & $\begin{array}{c}13^{* *} \text { piezas } \\
\text { periodísticas }\end{array}$ \\
\hline $\begin{array}{c}\text { Castro Castro } \\
\text { Lima, 27.04.2020 }\end{array}$ & $\begin{array}{c}\text { Primera ACR en una cárcel para hombres de Lima } \\
\text { donde la violencia de la represión se refleja en } \\
\text { internos fallecidos. Ya habían fallecidos por COVID- } \\
19 \text { en EP. }\end{array}$ & $\begin{array}{c}44 \text { piezas } \\
\text { periodísticas }\end{array}$ \\
\hline $\begin{array}{l}\text { Anexo Chorrillos } \\
\text { Lima, 10.05.2020 }\end{array}$ & $\begin{array}{l}\text { Primera ACR frente a COVID-19 en un } \\
\text { establecimiento penitenciario para mujeres reportada } \\
\text { por MCM. }\end{array}$ & $\begin{array}{c}11 \text { piezas } \\
\text { periodísticas }\end{array}$ \\
\hline * & $\begin{array}{l}\text { colectiva recibe cobertura mediática } \\
\text { aborda dos } A C R\end{array}$ & \\
\hline
\end{tabular}

Para la recopilación de las notas informativas se agotaron los términos 'protesta', 'motín', 'prisión', 'INPE', 'Río Seco', 'Picsi', 'Castro Castro' y 'Chorrillos' en los buscadores de los diarios elegidos, entre el 18 de marzo y el 12 de mayo del 2020. Quedó un total de 81 notas periodísticas informativas escritas (tabla 2). Después de seleccionar las notas periodísticas, se otorgó a cada una de ellas un código considerando el periódico de procedencia (ej. TRoo1, OJoo1, etc.) 
Tabla 2. Corpus de análisis.

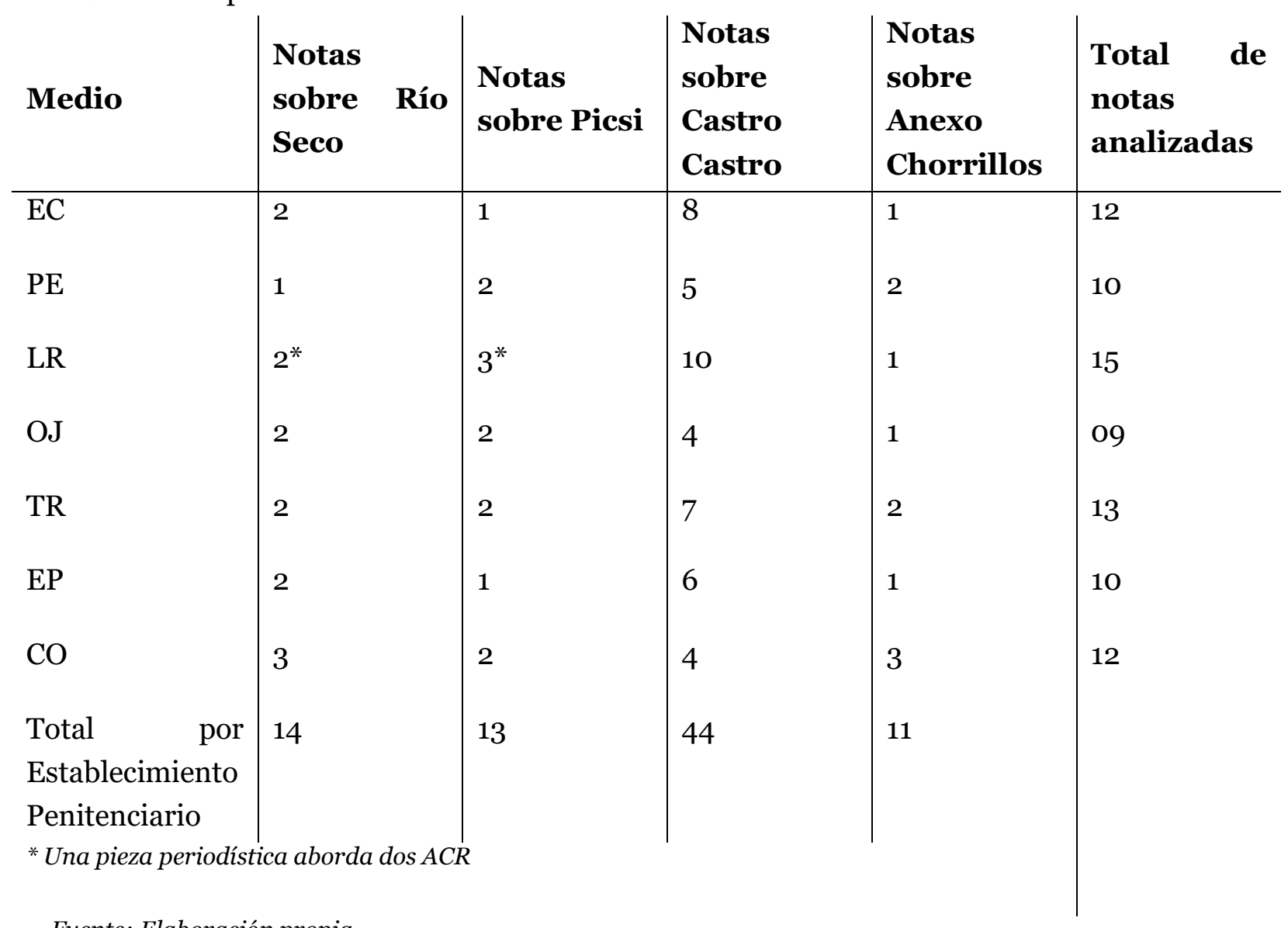

\subsection{Análisis de la información}

El análisis de los artículos se realizó a través del análisis crítico del discurso, en diálogo con la perspectiva de la teoría fundamentada. El análisis crítico del discurso busca explicar el rol de las estructuras discursivas en la legitimación y reproducción de dominación y desigualdad en las interacciones sociales. De la amplia gama de categorías de análisis propuestas por el análisis crítico del discurso, nos centramos en el abordaje de la situación comunicativa escenario y participantes a quienes se da voz- y de las estructuras del discurso macroestructuras semánticas, léxico y estructura de las oraciones- (Dijk, 2017). La teoría fundamentada implica generar conocimiento a partir de la interpretación de los significados simbólicos detrás de las acciones y estrategias comunicativas: partimos de los datos 
analizados, en este caso de las notas periodísticas, y desde ahí dialogamos con las teorías (Glaser \& Strauss, 2017; Páramo, 2015; Strauss \& Corbin, 2002).

La construcción de las categorías de análisis siguió un proceso inductivo acorde a los objetivos del estudio: se realizó una codificación abierta del texto escrito de cada pieza, abordando cada nota como unidad de análisis, lo que implicó separar para luego comparar los datos (Strauss \& Corbin, 2002). Cuatro investigadoras realizaron un análisis intersubjetivo sistemático de la totalidad de artículos, organizando categorías según tres subtemas emergentes de la data: explicación de los motivos de las ACR, descripción de las ACR y descripción de las personas recluidas. Luego, se buscó comprender los significados que los diarios otorgan al fenómeno (Dijk, 2018). Este proceso implicó identificar, en titulares y texto, temas y subtemas recurrentes, frecuencia de expresiones y formas de nombrar los eventos, estructuras activas versus pasivas en las oraciones según actor y acción referida, y procesos lingüísticos de citación como medio de inclusión de actores sociales a quienes se otorga o no la voz para argumentar la narración de los sucesos (Dijk, 2017; Pardo, 2007). El resultado evidenció tendencias en maneras de nombrar, explicar lo ocurrido y diferenciar según el sexo de las personas recluidas.

\section{Resultados y Discusión}

La cobertura de las ACR analizadas en el presente artículo fue la siguiente: a los eventos en Río Seco, Picsi y Chorrillos cada medio destinó entre 1 y 3 notas periodísticas (moda Río Seco y Picsi=2; moda Chorrillos=1). La cobertura de Castro fluctuó entre 1 y 10 piezas $(\operatorname{moda}=4)$, donde las primeras giraron en torno al evento en sí y las siguientes en torno a la corrección de la cantidad de fallecidos: ninguno, tres, nueve, ocho. Así, la cobertura fue en gradiente: en un extremo, hubo mayor reporte sobre el establecimiento penitenciario de varones en la capital, marcado por mayor violencia; a continuación, se cubrió establecimientos de varones en regiones donde la violencia fue matizada; y finalmente, establecimientos de mujeres, donde la violencia fue negada, aspecto que se analizará a lo largo de los siguientes acápites.

$\mathrm{Al}$ oligopolio mediático señalado previamente se suma que, en algunos casos, MCM de la misma editorial repiten de manera exacta, palabra por palabra, la información. Así, los MCM comparten una tendencia desde la cual construyen noticias que refuerzan estereotipos, en este caso, sobre los establecimientos penitenciarios y las personas recluidas. Las notas se han analizado como independientes a pesar de la repetición de su contenido. 
Tomando en cuenta el análisis de las notas periodísticas, en los siguientes acápites explicaremos cómo estas reproducen el imaginario social de la cárcel como institución total. Las ACR se reportan como expresión de crisis del poder institucional, deslegitimando el actuar de las personas recluidas, incluso en el marco de la emergencia sanitaria por COVID19. En consecuencia, se representa a las personas recluidas como personas sin capacidad de razonar o dialogar, con particularidades según si son hombres o mujeres. Es decir, la reconstrucción discursiva del fenómeno es atravesada por el género en distintos momentos: cómo se nombran las ACR, cómo se caracteriza a sus participantes y cómo responde la institución penitenciaria.

\subsection{Los motivos que impulsan las ACR según los diarios}

Siguiendo a Useem y Kimball (1991), la legitimidad de las ACR se basa en cuál grupo, autoridades o personas recluidas, narra los hechos. Al igual que reportan Pyrooz et al. (2020) sobre establecimientos penitenciarios en otros contextos y situaciones, en las notas analizadas hay una marcada tendencia a brindar explicaciones desde la perspectiva de las autoridades penitenciarias, invisibilizando las voces de la población penitenciaria. Asimismo, los diarios seleccionados se convierten en emprendedores morales que promueven, así sea de manera sutil, la indignación social (Cohen, 2002), ya que se han quebrado los valores asociados a instituciones totales como la seguridad y el orden, buscando deslegitimar o cuestionar las ACR. Desde la perspectiva de los diarios, las personas recluidas reclaman por múltiples razones: por temor, por la mejora de atención en salud, por los indultos penitenciarios, por quiebres en la programación y orden diario, por la precariedad de las condiciones de vida.

Principalmente, los diarios describen los sucesos y explican que las ACR se deben al temor al contagio de COVID-19, enmarcando lo ocurrido como parte del contexto de emergencia sanitaria a nivel nacional: "supuestamente por el temor de morir con el coronavirus" (COoo5, 21/03/2020), "por miedo al coronavirus" (EPoo4, 27/04/2020; TRoo8, 28/04/2020). Tras mencionar el miedo, sin embargo, en el mes de marzo se especifica que "no existe ningún caso de contagio por coronavirus" (TRoo1, 18/03/2020) y a partir de abril, se indica la presencia de COVID-19 pero se enfatiza la implementación de medidas de prevención y atención que toma la institución penitenciaria para controlar el contagio. Con ello, se resta fundamento al sentimiento enunciado. Al mismo tiempo, resaltar el temor como motivo principal que moviliza al colectivo, sin hacer mención a las condiciones 
estructurales que impulsan dicha emoción, difumina el sustento en que surge y se sostiene la emoción. Al omitirse o anularse el contexto en que surgen los reclamos, la lógica de las acciones colectivas se deslegitima.

Una segunda explicación utilizada es que las personas recluidas reclaman por la mejora en la atención en salud para enfrentar la pandemia dentro de los EP. Se sostiene que solicitan la toma de pruebas, la entrega de medicamentos y mascarillas, la asistencia de médicos para atender a las personas con síntomas y el remover los cuerpos de las personas fallecidas. Esto sin especificar, por ejemplo, que al inicio de la pandemia, el instituto penitenciario contaba con 64 médicos a nivel nacional para una población penitenciaria de 97111 personas detenidas, con un marcado centralismo en la capital del país (Defensoría del Pueblo, 2020). En el caso de los centros penitenciarios de mujeres, se suma el reclamo de retirar a niños/as que conviven con ellas hasta que cumplen los tres años. Como se explicará con mayor detalle al momento de analizar las notas periodísticas de las ACR sobre mujeres.

En relación con el reclamo de atención en salud, cuatro notas periodísticas definen los reclamos como "beneficios sociales", mientras ninguna alude expresamente al derecho a la salud. Las medidas de prevención y atención de COVID-19 son ubicadas como un privilegio, omitiendo la responsabilidad del Estado de garantizar la salud a las personas encarceladas (CIDH, 2020). Como menciona Cohen (2002), las personas que se han desviado de la norma siempre serán juzgadas a partir de ese estatus y se buscará castigarlas reiteradamente, en este caso, incluso con la muerte.

La tercera explicación gira entorno al reclamo por oficializar y agilizar indultos penitenciarios. Como medida para reducir el riesgo de contagio masivo se propuso disminuir el hacinamiento de los establecimientos penitenciarios, que en Perú excede la capacidad en 55411 personas (INPE, 2020). A través de la promulgación de indultos, conversiones de pena y disminución de prisión preventiva, el Estado estableció la meta de liberar 10000 personas en un mes (DS-004-2020-Jus, 23 de abril de 2020). La ACR reportada luego de este decreto incluyó entre sus reclamos el tema de las liberaciones, que uno de los MCM analizados cubrió de la siguiente manera: “... decenas de internos quemaron colchones y colgaron carteles con demandas de libertad” (ECo10, 29/04/2020).

Para informar sobre este punto, los artículos de los MCM en plataformas digitales analizados otorgan la voz principalmente a las autoridades penitenciarias, cuyas explicaciones están 
acompañadas por la imposibilidad de aplicar la medida: "tiene que ver básicamente con el tema de los indultos, pero por el tipo de delitos no están incluidos algunos internos" (ECoO4, 27/04/2020). Entonces, si bien hay un motivo que puede ser considerado lógico dada la lentitud de los procesos legales, se vuelve a deslegitimar la demanda de la ACR en conjunto, esta vez sustentado en el grado de transgresión de delitos específicos, argumento que ha sido estudiado durante la pandemia en el contexto estadounidense (Lofaro \& McCue, 2020). Algunas notas incluso exponen que las personas recluidas reclaman "libertad", sin mencionar el entorno político sobre indultos a los que se puede acceder, descontextualización que convierte el reclamo en aún más irracional y lo deslinda de la realidad social que lo explicaría. Ante ello, cabe mencionar que, tras 100 días de emergencia sanitaria, se logró sólo 16 \% de la meta propuesta para abril (Ministerio de Justicia y Derechos Humanos, 2020).

Como cuarta explicación, algunas notas periodísticas se distancian del contexto de emergencia sanitaria para señalar que, sumado al temor por contagio de COVID-19, los motivos se centran en temas ligados a la programación diaria y al orden de cada establecimiento penitenciario. Por un lado, en referencia a la programación diaria, hay una tendencia a señalar que el mayor pedido es la recuperación de las visitas. En una situación de emergencia sanitaria, donde el mandato de protección a nivel nacional es el distanciamiento social, el reclamar por la recuperación de las visitas parece ser, nuevamente, un pedido impulsado por la irracionalidad, lo cual refuerza la deslegitimación de las ACR. Por ello, resulta importante señalar que solo una nota de las 81 analizadas explica que los familiares cubren las deficiencias del Estado, como el abastecimiento de comida y medicinas. En ningún caso se hace referencia al derecho a la comunicación (CIDH, 2008), también vulnerado en este escenario. En las notas periodísticas no se problematizan los limitados medios económicos, la poca disposición política de las autoridades o las posibles estrategias a implementar para que las personas recluidas mantengan contacto con sus familiares.

Por otro lado, en relación con el orden, se sostiene que las ACR buscan el cambio de autoridades, esconder intentos de fuga o resolver conflictos entre las personas recluidas, dejando en segundo plano el reclamo por el derecho a la salud y a la vida. Por ejemplo, se señala: "al parecer, esta gresca de hampones se debe al control de la venta de drogas" (COo05, 21/03/2020). Las notas que refieren intentos de fuga le dan la voz nuevamente a las autoridades, que transmiten la intencionalidad de transgresión absoluta al orden institucional. En este punto cabe retomar la capacidad de los MCM para infundir pánico 
(Cohen, 2002): de las 81 notas periodísticas analizadas, solo una señala la ambigüedad en los comunicados de las autoridades:

Lo que sucedió ese día es confuso. Los reclusos habrían quemado colchones y, según la autoridad penitenciaria, preparaban una fuga masiva. El INPE no ha precisado ni dado ningún detalle de cómo y por qué área del penal sería la fuga. (LRo13, 02/05/2020)

Finalmente, un punto que es escasamente mencionado es que las personas recluidas reclaman por la precariedad y hacinamiento de los establecimientos penitenciarios, definiéndolas como espacios idóneos para la propagación de la COVID-19. En los establecimientos penitenciarios abordados en el presente estudio, por ejemplo, la sobrepoblación es de 310 \% (Picsi), 199 \% (Río Seco), 375 \% (Castro Castro) y 56 \% (Anexo Chorrillos) (INPE, 2020). Contextualizar y caracterizar los establecimientos penitenciarios como instituciones con múltiples carencias estructurales otorga una justificación racional a las ACR. Sin embargo, en comparación con todas las explicaciones brindadas, esta justificación se presenta de manera esporádica. Deslegitimar el razonamiento detrás de las demandas anula las posibilidades de diálogo y limita las posibilidades de respuesta a las necesidades de las personas recluidas, dejando espacio únicamente para el control autoritario y la represión (Greer \& Reiner, 2012).

\subsection{Establecimientos penitenciarios para hombres: ACR definidas como motín}

En esta sección presentaremos cómo los MCM analizados en este artículo abordan las ACR en establecimientos penitenciarios de hombres concentrándose en la ilegitimidad de la disputa de poder y en la transgresión de normas. Difunden un molde de hombre recluso estereotipado caracterizado por intensos afectos negativos y poco razonamiento que medie la conducta. Esta mirada deja entrever que subyace la tendencia a justificar la represión institucional como única respuesta posible (Kidd-Hewitt, 1995; Moreno, 2016). 


\section{Descripción de las ACR en establecimientos penitenciarios para hombres.}

Los MCM seleccionados usan palabras asociadas al enfrentamiento con la autoridad y al uso de violencia por parte de los internos. El 71,25 \% de titulares sobre las ACR de varones revisadas incluye la palabra "motín" o "amotinamiento". También se incluye, en titulares y textos, referencias a levantamientos, actos vandálicos, reyertas e indisciplina. Si bien sólo dos notas explicitan que hubo destrozos o destrucción de las instalaciones, fue frecuente la referencia a la quema de colchones y al humo, aludiendo a daños materiales. Las descripciones de los eventos sugieren un movimiento que, de manera desordenada, toma espacios del EP, anticipando una escalada de violencia. Así, las ACR en establecimientos penitenciarios se suelen definir a partir de enfrentamientos en contra del poder de la autoridad, denotando una pugna sobre el control dentro de la misma.

Los siete MCM analizados incluyeron indistintamente referencias al acto de protestar y de amotinarse dentro de la misma narrativa. $\mathrm{Al}$ respecto, Desta (2019) señala que las protestas en cárceles difieren de otras formas colectivas de acción, como motines y rebeliones, en tanto son formas pacíficas de resistencia. La mayoría de MCM analizados no considera esta diferenciación al referirse a ACR en establecimientos penitenciarios para varones. En el corpus resalta una publicación que relata el desarrollo del evento como una protesta que se convierte en un motín:

Lo que empezó, cerca de las 2 p.m., como una protesta de los doce pabellones del penal Castro Castro escaló, en cuestión de minutos, en un motín por el temor de los internos a contagiarse masivamente del COVID-19. Al menos tres pabellones decidieron levantarse contra las autoridades. La situación fue controlada pasada las 3:20 p.m., según informó el jefe del Instituto Nacional Penitenciario (INPE), Gerson Villar. (PEoo4, 27/04/2020)

Useem (2018), al definir un motín, plantea que este representa la pérdida del control por las autoridades durante una cantidad significativa de tiempo. La actividad que en un lapso de 80 minutos incluye protesta, motín y sumisión nos lleva a cuestionar los parámetros considerados por las autoridades penitenciarias y los MCM como duración significativa que amerita la denominación de motín y la respuesta acorde a ella.

Las notas periodísticas, además, señalan que no todos los reclusos se "levantan” en las ACR, pues detallan que solo se "toman" algunas instalaciones de los establecimientos penitenciarios, delimitando en la narración que son espacios específicos como pabellones o 
patios donde ocurren estos hechos. Hay énfasis en que no todo el establecimiento se encuentra "amotinado" y que, por tanto, no se ha perdido todo el control. Además, la narración divide a la población recluida en dos grupos diferenciados: aquellos que se amotinan y aquellos que no.

\section{Caracterización del interno que participa en una ACR.}

Identificamos una descripción constante del interno que se amotina en establecimientos penitenciarios para hombres, mientras se relega la del interno que no lo hace. A través de la narración de los eventos, se muestra una imagen de multitud homogénea, caracterizada por la transgresión y la agresividad como guía de su conducta. En esta sección mostraremos la forma en que, en las notas periodísticas, los internos tienden a ser presentados como autores de actos de alta emoción e impulsividad, bajo razonamiento y marcados por violencia y destrucción.

La representación de los internos en los MCM analizados reproduce la lógica ambivalente de las cárceles modernas, mostrando la tensión existente entre los objetivos punitivos, orientados a la vigilancia y el castigo, y los objetivos de rehabilitación que pretenden resocializar y reinsertar en la sociedad. Revisemos como ejemplo dos viñetas sobre el mismo suceso.

(i) En las siguientes horas, difundieron a la prensa videos grabados con celulares por los reclusos en los que pedía que no los dejen morir dentro del penal, convertido en un foco de propagación de la enfermedad. Los celulares no están permitidos en la población penal, pero los reclusos se las agencian para tenerlos y desde allí se comunican con sus familiares, entre otros. (LRo13, 02/05/2020)

(ii) Los videos fueron registrados por un interno del recinto, quien asegura que los tienen totalmente abandonados y "nadie dice nada". "Nos están matando acá, todos nos estamos muriendo y nadie dice nada. Nadie dice la verdad y la gente se está muriendo acá en el penal Castro Castro señores", dice uno de los presos, quien seguido de ello grita iLibertad! (EPoo4, 27/04/2020)

La nota (i) se enfoca en la ruptura de las reglas, mientras que la (ii) se centra en la denuncia y la demanda de los internos. El contraste de ambos fragmentos evidencia la alianza que algunos de los MCM analizados establecen con el imperativo de control; una constante en 
las notas sobre ACR en establecimientos penitenciarios durante la emergencia sanitaria. Desde ahí, la construcción del interno tipo gira mayoritariamente en torno a la transgresión. De la mano de una institución que pregona la reinserción social como misión, pero en su lógica no encuentra las formas de favorecerla efectivamente, encontramos una transmisión mediática estereotipada que dificulta concebir la reinserción social luego del delito y que contiene una mirada del crimen como decisión individual, sin incorporar las precariedades en la estructura social en la que se enmarca (Greer \& Reiner, 2012). El cinismo generalizado hacia la resocialización cobra sentido en este marco (Behan, 2014).

Para entender la imagen del interno construida en los MCM incluidos en este análisis cabe volver al motivo principal que brindan las notas periodísticas para explicar las ACR: el temor al contagio del COVID-19. Klandermans (2017) reconoce que, en las protestas, las emociones y razonamientos se entretejen y ambos son centrales en la motivación y compromiso con el proceso de denuncia y búsqueda de cambio. Esta complejidad es anulada en las notas periodísticas, donde se transmiten personas unidimensionales (Moreno, 2016) al resaltar el impulso afectivo como guía de la conducta e invisibilizar o deslegitimar su razonamiento.

Eliminar la lógica detrás de los reclamos de los internos deja de lado el contexto institucional precario donde se puede generar el contagio masivo, la incapacidad de respuesta médica y los vacíos institucionales cubiertos por las visitas, ahora ausentes. Asimismo, no se cuestiona en ninguna nota periodística posibles manejos institucionales ineficientes previos a las ACR, aunque estos eventos suceden por una respuesta insatisfactoria ante momentos anteriores de tensión (Easton, 2018). Como señalamos en la introducción, en la práctica, los establecimientos penitenciarios de Latinoamérica operan a través de negociaciones que implican la multidireccionalidad del poder, aspecto que no es incorporado en las notas informativas revisadas: los eventos son, más bien, narrados sin referir procesos o acercamientos previos a la explosión de la violencia dentro de los establecimientos penitenciarios.

En esta acción narrada en las piezas periodísticas como impulsiva e irracional, el interno es sujeto únicamente desde la acción violenta y la capacidad de destrucción con la finalidad de subvertir el poder institucional. Además, se podría señalar que las ACR dentro de los establecimientos penitenciarios estarían subvirtiendo el orden esperado de las mismas, pues permiten a los internos pasar de objetos de control a sujetos de derecho. Si bien los MCM analizados exponen la capacidad de denuncia de los internos, esta no es concebida como una

Perspectivas de la Comunicación - Vol. 14 - No 1 - 2021 - pp. 169-203

Universidad de la Frontera - Chile 
acción por parte de agentes de cambio social enmarcados en el proceso de resocialización mencionado previamente, sino como actos de desobediencia. Ello, vinculado a la impulsividad y agresión, convierte al interno-sujeto-denunciante en interno-sujetoamenaza.

A través de un comunicado, [el Instituto Penitenciario] detalló que prisioneros de 9 de los 14 pabellones del recinto penitenciario protagonizaron actos de violencia y vandalismo, iniciando un motín provisto de armas punzo penetrantes y objetos contundentes, con quema de colchones y destrucción de parte de la infraestructura interna de los pabellones, logrando subir a los techos con el objetivo de impedir el acceso de los policías, arrojándoles piedras y demás objetos. (ECo07, 28/04/2020)

Las reconstrucciones de los eventos al estilo de la cita anterior son frecuentes. En ellas, el interno-sujeto-amenaza encuentra cabida en el discurso de la prensa cuando reta a la institución a recuperar el control y, con ello, a devolverlo a su posición de objeto. De esta forma, los recursos individuales y colectivos para ubicarse como sujetos de derecho y, a través de ello, performar la resocialización ansiada por el sistema penitenciario moderno, son eliminados del imaginario colectivo. Así, desde los discursos de los MCM incluidos en el análisis, parecería que los internos logran afirmarse como sujetos a través de la fuerza, la violencia, la búsqueda de dominación del poder considerando su propia satisfacción. Estas características estarían asociadas a una representación tradicional de masculinidad (Connell, 2005) y que consideramos moldea la manera cómo se responde desde las autoridades. La conexión entre representaciones de género y respuestas institucionales podría ser un eje para profundizar en futuras investigaciones.

\section{La respuesta institucional en establecimientos penitenciarios para varones según los diarios analizados.}

Las notas periodísticas refieren que la respuesta de la institución tiene como objetivo restablecer el orden y control dentro de los establecimientos penitenciarios como forma de finalizar las ACR. La numerosa cantidad de participantes reportada y el alto grado de violencia atribuido a los internos en las piezas periodísticas preparan al público para asumir que el camino para terminar las tres ACR en establecimientos penitenciarios para varones requiera el ingreso de personal penitenciario, policía y/o Fuerzas Armadas del Perú.

Estas respuestas se encuentran prioritariamente vinculadas al uso de la fuerza por parte del Estado frente a los internos. Por ejemplo: "Personal de seguridad del INPE trató de 
recuperar el control y fue que se produjo un enfrentamiento y como consecuencia de ello dos de los agentes resultaron heridos. [...] Una hora después, los agentes retomaron el principio de autoridad" (PEoo3, 19/03/2020). Además de la importancia de retomar el orden y el control, se explicita el "principio de autoridad" bajo el cual se rige la respuesta, enmarcada en una institución donde se espera que las autoridades retengan el control, incluso si ello requiere el uso de fuerza. Este principio base refuerza la imagen de una institución inflexible ante la desobediencia.

En oposición a la narración de acciones violentas consideradas irracionales por parte de los internos, la trasgresión de límites y uso de la violencia por parte de la institución se exponen como actos esperables. Sus secuelas, "personas heridas" (LRoo1, 19/03/20), "internos que resultaron heridos" (COOO3, 19/03/2020), "internos habrían fallecido por politraumatismo por arma de fuego" (PEoo6, 28/04/2020), no se cuestionan. En algunos casos, se comparte puntualmente la declaración del presidente del instituto penitenciario "han informado que hay tres fallecidos. Se están investigando las causas. No se han utilizado armas de fuego, se utilizan escopetas de perdigones" (EPoo6, 27/04/2020; PEoo6, 28/04/2020). Estas frases, desde estructuras pasivas y con menor detalle en la reconstrucción de la violencia, encubren al sujeto que hiere, que dispara, que ejerce violencia. De esta forma, como expone Teun van Dijk (2017) en otros contextos, se influye en la cognición del público, minimizando las acciones negativas por parte de agentes estatales. Entre decenas de notas periodísticas en esta línea, sin embargo, se encuentra alguna que rescata las denuncias de agresión por parte de efectivos policiales en voz de los internos y sus familiares.

Este abordaje del uso de represión violenta por las notas periodísticas revisadas reproduce el imaginario de control como antídoto ante la amenaza a la seguridad social (Greer \& Reiner, 2012): cuando reprime, el Estado cuida a sus (buenos/as) ciudadanos/as. En esta línea, los diarios revisados suelen convertirse en cajas de resonancia de la autoridad institucional cuando sustenta su razón de ser en declaraciones de estar en proceso de- o haber logrado ya "retomar el control y calma a los internos" (ECo01, 18/03/20; TRoo1, 18/03/20; LRoo2, 20/03/20). Así, la represión de la ACR parece perfilarse como la única salida posible, que además no se expone como acción violenta, ni por las autoridades penitenciarias ni por los medios que cubren la noticia.

Como hemos indicado, en las últimas dos décadas, se han evidenciado las formas en que sistemas penitenciarios latinoamericanos se sostienen en la negociación formal e informal 
con dinámicas y organizaciones de internos, ya sea desde la construcción de alianzas o desde la no confrontación a acciones ilegales mientras ayuden a mantener orden (Bracco, 2021; Darkes \& Garcés, 2017; Veeken, 2000). Por tanto, la otra cara de la moneda queda en la sombra de los discursos mediáticos. Esta línea de investigación permite imaginar formas alternativas para responder a ACR en la cárcel, como espacios de diálogo o respuesta a las demandas.

\subsection{Establecimientos penitenciarios de mujeres: $A C R$ definidas como no- motín}

En esta sección nos detendremos a explicar cómo los MCM analizados exponen las ACR de mujeres como acciones que no confrontan a la autoridad, descartan la posibilidad de violencia y presentan a las mujeres recluidas como sumisas ante la autoridad y el sistema. Ante ello, las respuestas institucionales referidas no contemplan la represión, sino la garantía de medidas de prevención y respuesta ante contagios.

Es necesario señalar que las notas periodísticas tienden a usar de manera indiferenciada los nombres Santa Mónica y Anexo de Chorrillos, que corresponden a dos establecimientos penitenciarios distintos. No logran un consenso sobre en cuál ocurrió la ACR: "Un grupo de internas del Penal Anexo de Mujeres de Chorrillos, conocido como Santa Mónica, rompió la tranquilidad de la noche de este domingo con desesperados gritos de auxilio..." (LRo16, 11/05/2020). La confusión en el nombramiento refleja una posible estandarización de la población penitenciaria de mujeres, a quienes se invisibiliza, sin poder siquiera ubicarlas correctamente en el espacio y en el encierro. El único referente estable para identificar de qué establecimiento penitenciario se trata es que en 7 de las 11 piezas se nombra a una mujer recluida conocida por haber sido funcionaria pública.

\section{Descripción de las ACR en establecimientos penitenciarios para mujeres.}

$\mathrm{Al}$ referirse a ACR en establecimientos penitenciarios para mujeres, la palabra "motín" apareció como acción descartada; en su lugar, fueron denominadas protestas pacíficas (tabla 3). 
Tabla 3. Titulares de piezas periodísticas sobre ACR en Establecimientos Penitenciarios de mujeres.

\begin{tabular}{|c|c|c|}
\hline Tema & $\begin{array}{l}\text { Frecuencia } \\
(\mathbf{N}=\mathbf{1 1})\end{array}$ & Viñetas \\
\hline $\begin{array}{l}\text { Descarte de reclamo que } \\
\text { confronta a la autoridad }\end{array}$ & 4 & $\begin{array}{l}\text { "INPE descarta motín..." (EPo10, } \\
\text { 11/o5/2020; TRo13, 11/o5/2020; PEo10, } \\
\text { 11/o5/2020; ECo12, 11/o5/2020) }\end{array}$ \\
\hline Pedido de ayuda & 4 & $\begin{array}{l}\text { “... gritan por ayuda tras nuevos casos por } \\
\text { COVID: "no queremos morir, ayúdennos"” } \\
\text { (TRo12, 10/05/2020) }\end{array}$ \\
\hline & & $\begin{array}{l}\text { "piden rescate de sus hïos" (LRo16, } \\
11 / 05 / 2020)\end{array}$ \\
\hline Protesta focalizada & 2 & $\begin{array}{l}\text { “... protestaron por mayor atención médica” } \\
(\mathrm{COOo} 8,11 / 05 / 2020) \\
\text { “... protestaron ante retorno de interna que } \\
\text { dio positivo al COVID-19” (OJoo9, } \\
11 / 05 / 2020)\end{array}$ \\
\hline Anuncio de contagios & 1 & $\begin{array}{l}\text { "Coronavirus llega al penal de Chorrillos” } \\
\text { (COoo9) }\end{array}$ \\
\hline
\end{tabular}

La forma de nombrar las acciones es un continuo de declaraciones de autoridades penitenciarias citadas en las notas, quienes rechazaron categóricamente el ejercicio de la violencia en lo acontecido: "El Instituto Nacional Penitenciario (INPE) descartó que se haya tratado de un amotinamiento, y por el contrario apuntó a una "protesta pacífica" (LRo16, 11/05/2020). Frente a ello, resalta el reporte de pancartas y banderas blancas sin referencia a la toma de instalaciones o destrucción de propiedad.

A diferencia de las ACR de hombres en las que se narra la predominancia de la violencia, en el caso de las mujeres se resaltan gritos desde el interior de sus celdas, durante la noche, que son escuchados por los vecinos que habitan cerca del establecimiento penitenciario. En los textos, las expresiones son catalogadas como gritos de desesperación, gritos desgarradores. Así, en la reconstrucción de los MCM, el accionar en establecimientos penitenciarios para 
mujeres sería también desordenado y difuso, pero sin quebrar el principio de autoridad o romper el orden institucional.

Al narrarse de manera tan diferenciada, sostenemos que el amotinarse o no, así como los discursos sobre ello, son fenómenos atravesados por nociones de género. Las narraciones de los MCM seleccionados repiten el patrón identificado por Easton (2018), de asociar los motines con los internos hombres. Como se sostuvo anteriormente, el hecho que las cárceles sean una institución patriarcal que re-feminiza y que promueve mayor control hacia la población penitenciaria femenina, disminuye las posibilidades de las mujeres privadas de libertad de realizar una acción organizada que confronte y transgrede el (des)orden institucional (Bex, 2016; Bosworth \& Kaufman, 2013).

\section{Caracterización de la interna que participa en una ACR.}

La representación de las mujeres recluidas se construye en los MCM analizados desde la sumisión y disciplina, concibiendo sus pedidos desde el sistema, y no contra este: "desde las ventanas de sus celdas" (COoO7, 10/05/2020), "las presas solo realizaron una "protesta pacífica” por mejores condiciones" (LRo16, 11/05/2020). Es decir, ellas respetan el orden oficial establecido en la dinámica del establecimiento, y se cataloga la acción de reclamo como un hecho aislado: "Las reclusas realizaron una inusual protesta porque temen por la salud de los menores" (COoo7, 10/05/2020).

La ACR de las mujeres, si bien se sustentan también en afectos negativos y nuevamente el peso se pone en la emoción sobre la razón, como ocurría en los textos sobre ACR en establecimientos penitenciarios de varones, esta vez la emoción no se vincula a actos violentos sino a desesperación y búsqueda de empatía. Así, la construcción mediática de las mujeres recluidas se aleja de los estereotipos sobre la criminalidad y abraza rasgos atribuidos a la feminidad tradicional, especialmente al sufrimiento y el rol materno. Como se mencionó, en los discursos de las notas periodísticas cobra especial importancia la alusión a los gritos que se escuchaban desde fuera del establecimiento penitenciario, y el uso de palabras como “desgarradores" (LRo16, 11/05/2020) y “clamor” (PEoo9, 10/05/2020). Una nota periodística incluso describe la situación como "trágica” (TRo12, 10/05/2020).

A pesar de que en el imaginario social las mujeres recluidas suelen ser víctimas de una doble estigmatización por haber delinquido y no cumplir con los roles tradicionales de género (Pérez-Correa, 2013), en las notas periodísticas las ubican en una posición de víctimas que buscan ser ayudadas, donde su actuar despierta compasión. Consideramos que esto se 
incrementa al definir a las internas que reclaman como madres, aspecto mencionado por tres de los siete diarios analizados. En ese sentido, los gritos estarían subsanando el quiebre de su rol tradicional de género y permitiéndoles recuperar el papel de las mujeres en una sociedad patriarcal: ser madres cuidadoras.

Los gritos de angustia como guías de la narración eliminan la capacidad de razonamiento de las mujeres y las posicionan como sujetos que no cuentan con argumentos acerca de su situación y propuestas para hacerle frente. En contraparte, el día 15 de mayo, mujeres recluidas en Anexo Chorrillos escribieron una carta colectiva que fue difundida por redes sociales y en medios digitales de menor alcance (Redacción Mano Alzada, 2020). En ella, argumentan sus necesidades y hacen un llamado a las autoridades para desarrollar estrategias de prevención efectivas. Si bien la carta se encuentra fuera de nuestro rango de análisis metodológico, nos parece interesante mencionar que no fue difundida en ningún diario seleccionado, reforzando en el imaginario que las internas actúan sin agencia ni racionalidad.

\section{La respuesta institucional en establecimientos penitenciarios para mujeres según los diarios analizados.}

Ante la ACR en la cárcel de mujeres, las notas periodísticas resaltan que el INPE brinda información específica sobre la situación de COVID-19 y asegura el abastecimiento de medicinas y oxígeno, la cobertura de atención médica, la habilitación de espacios para el aislamiento y la fumigación de tres establecimientos penitenciarios de la zona que albergan mujeres. Así, el foco de la respuesta está en atender a las demandas y exponer un Plan de Contingencia del COVID-19: "el INPE garantizó que en el Penal Anexo de Mujeres se viene ejecutando el mismo Protocolo de Contingencia que surtió efecto en el establecimiento penitenciario del Callao" (LRo16, 11/05/2020), “el INPE continuará con la implementación de las áreas de aislamiento, proveyendo oxígeno y otros medicamentos...” (ECo12, 11/05/2020).

Solo en un caso -específicamente en el diario que más notas periodísticas otorgó al evento en el EP para mujeres (3) y que en todas ellas mencionó la presencia de niños en el establecimiento penitenciario -se hizo referencia a la intervención de agentes del instituto penitenciario: "La noche del domingo se activó la protesta, pero agentes del INPE intervinieron para calmar a las internas" (COo09, 12/05/2020). La ausencia del discurso de control y la eliminación del despliegue de fuerza se traduce en esfuerzos destinados a calmar

Perspectivas de la Comunicación - Vol. 14 - No 1 - 2021 - pp. 169-203

Universidad de la Frontera - Chile 
la carga emotiva mencionada previamente. De esta forma, en las notas periodísticas sobre ACR en establecimientos penitenciarios peruanos, las mujeres parecen no ser percibidas como posibles amenazas al orden establecido, sino que actúan desde el respeto y en alianza a la jerarquía de poder necesaria para el funcionamiento penitenciario desde la lógica punitiva. La narrativa ubica el peso en la posición de víctima dócil, sin reconocer su capacidad de organización adaptada al contexto y a las posibilidades dentro de una institución total.

\section{Conclusiones}

Los MCM que se incluyen en este artículo, invisibilizan la complejidad de la realidad penitenciaria y las identidades de las personas que la conforman (Desta, 2019). El análisis de la descripción de los eventos y cómo, a través de ella, se construye una imagen única del interno hombre violento y transgresor, permite concluir que los MCM analizados asumen dos funciones a nivel social. Por un lado, sus discursos, entendidos como actos sociales, respaldan la necesidad de la cárcel como institución punitiva, donde se presenta a quienes la habitan únicamente como transgresores, lo que legitima castigos sobre ellos incluso cuando violan derechos fundamentales. Así, parecería que los MCM seleccionados perpetúan alianzas con discursos que validan castigo y represión.

Por otro lado, la transmisión de estos discursos también cumple una función de modelamiento hacia los/las ciudadanos/as considerados libres: se difunde un mensaje que infunde miedo de los posibles castigos frente al quiebre de las normas legales y posiciona al uso de la represión y la violencia de estado como medio aceptable para controlar a la población. En ambos casos, prevalece la centralización del poder como aquello que preserva el orden y autoridad, y se fomenta una alianza entre el panóptico (autoridades que controlan) y el sinóptico (lectores/as que avalan). El presente artículo se suma a las líneas de investigación que buscan complejizar la mirada para reconocer y fortalecer las formas alternas de funcionamiento de las cárceles y, desde ahí, considerar otras lecturas de la realidad social y la posibilidad de establecer procesos que utilicen el diálogo para construir respuestas alternativas a la violencia utilizada en las ACR.

Atribuciones tradicionales de género atraviesan las narraciones sobre ACR y personas recluidas, respondiendo a una distinción binaria de género que hemos incorporado al análisis. Si bien al abordar otras temáticas los MCM pueden incluir discursos más fluidos de 
género, no es el caso en las piezas analizadas. Como señala Easton (2018), la investigación acerca del des-orden tiende a enfocarse en cárceles de hombres, centrándose en las luchas de poder y las situaciones de violencia, mostrando un tipo de masculinidad asociada a la transgresión e impulsividad. En el caso de los establecimientos penitenciarios para mujeres, sumado al hecho de que son mucho menos estudiados en comparación a los de hombres, las investigaciones se enfocan en su vulnerabilidad antes y durante su encarcelamiento. No negamos las inequidades que viven las mujeres presas en relación con sus pares hombres, pero incidimos en la importancia de cuestionar imaginarios hegemónicos paternalistas, basados en imágenes parciales, donde se posiciona a las internas como personas que esperan ser rescatadas, sin control sobre su propia vida (Fili, 2013).

El análisis presentado en el artículo es una primera exploración a un tema que merece atención. A futuro, será importante complementarlo con otros discursos escritos y audiovisuales, como columnas de opinión, publicaciones en redes sociales, comentarios de lectores/as, así como con otros MCM como radio, cine y televisión. Asimismo, si bien se analizaron los diarios más leídos a nivel nacional, MCM regionales que no se incorporaron en esta oportunidad podrían incluir representaciones distintas.

Finalmente, cabe resaltar que el acto de reclamar a las autoridades la implementación de medidas es en sí mismo un acto de agencia y un reconocimiento de las instancias responsables, incluso cuando el medio utilizado es la transgresión. Enfocarse únicamente en el medio utilizado para el reclamo aplana la imagen de la población recluida y niega posibilidades de resocialización a sujetos de derecho en potestad de denunciar falencias del Estado que urgen respuesta. Así, el foco en el control social identificado en los MCM analizados sacrifica su potencial rol de mediación entre intereses de sectores de poder y respuestas a desigualdades sociales.

\section{Conflicto de interés}

Los autores declaran que no existe conflicto de interés. 


\section{Referencias bibliográficas}

ALTO COMISIONADO DE LAS NACIONES UNIDAS PARA LOS DERECHOS HUMANOS (2014): Protesta Social y Derechos Humanos: Estándares Internacionales y Nacionales. Santiago (Chile), Instituto Nacional de Derechos Humanos. http://acnudh.org/wpcontent/uploads/2015/04/PROTESTA-SOCIAL.pdf

BEHAN, C. (2014): Learning to Escape: Prison Education, Rehabilitation, and the Potential for transformation. Journal of Prison education and reentry, 1(1), pp. 20-31. http://dx.doi.org/10.15845/jper.v1i1.594

BERGMAN, M. (2020): Insights from New Studies on Violence in Latin American Prisons. International Criminal Justice Review, 30(1), $\quad$ pp. https://doi.org/10.1177/1057567719896160

BEX, L. (2016): Women doing life. Gender, Punishment and the Struggle for Identity. New York, NYU Press.

BOSWORTH, M. \& KAUFMAN, E. (2013): Gender and Punishment. En J. Simon y R. Sparks (Eds.), The SAGE Handbook of Punishment and Society (pp. 186-204). Los Angeles (CA), SAGE Publications Ltd.

BRACCO, L. (2021): Living behind symbolic and concrete barriers of total institutions: Reflections on the transition between domestic symbolic patriarchal imprisonment and cogoverned, state-sponsored incarceration in Perú. International Journal for Crime, Justice and Social Democracy, 10(1), pp. 52-64. https://doi.org/10.5204/ijcjsd.v10i1.1554

CABAnEllas, G. (2012): Diccionario Enciclopédico de Derecho Usual. Buenos Aires, Editorial Heliasta.

CARRABINE, E. (2005): Prison Riots, Social Order and the Problem of Legitimacy. British Journal of Criminology, 45, pp. 896 - 913. https://doi.org/10.1093/bjc/azio52 
CENTRO DE ESTUDIOS LATINOAMERICANOS SOBRE INSEGURIDAD Y VIOLENCIA (CELIV) (2020): Los efectos del coronavirus en las cárceles de Latinoamérica. Sociedad de Criminología Latinoamericana.

https://criminologialatam.wordpress.com/2020/06/12/efectos-del-covid-19-carceles-delatino-america

COHEN, S. (2002): Folk Devils and Moral Panics. The Creation of the Mobs and the Rockers. Londres, Routledge.

COMPAÑÍA PERUANA DE ESTUDIOS DE MERCADO (2016): Estudio de lectoría de diarios en Lima y 15 principales ciudades. $C P I$.

https://cpi.pe/images/upload/paginaweb/archivo/23/LectoriaDiarios 2016.pdf

CONNELL, R. (2005): Masculinities (2da Edición). Cambridge, Polity Press.

CORTE INTERAMERICANA DE DERECHOS HUMANOS (o8 de mayo 2020): CIDH condena hechos de violencia en cárceles peruanas. OEA.

http://www.oas.org/es/cidh/prensa/comunicados/2020/107.asp

(marzo 2008): Principios y Buenas Prácticas sobre la Protección de las Personas Privadas de libertad en las Américas. http://www.oas.org/es/cidh/mandato/Basicos/PrincipiosPPL.asp

CUNHA, M. (2014): The Ethnography of Prisons and Penal Confinement. Annual Review of Anthropology, 43(1), pp. 217-233. https://doi.org/10.1146/annurev-anthro-102313-030349

DARKE, S. \& GARCÉS, C. (Eds.) (2017): Informal dynamics of survival in Latin American prisons. Prison Service Journal, 229, pp. 1-62.

https://www.crimeandjustice.org.uk/sites/crimeandjustice.org.uk/files/PSJ\%20229\%20J anuary\%202017.pdf

DESTA, Y. T. (2019): Striking the right balance: toward a better understanding of prison strikes. Harvard Law Review, 132(5), pp. 1490-1519.

https://www.questia.com/library/journal/1G1-577668151/striking-the-right-balancetoward-a-better-understanding

Perspectivas de la Comunicación - Vol. 14 - No 1 - 2021 - pp. 169-203

Universidad de la Frontera - Chile 
DIJK, T. A. (2017): Análisis crítico del discurso. Revista Austral de Ciencias Sociales, 30, pp. 203-222. https://doi.org/10.4206/rev.austral.cienc.soc.2016.n30-10

(2018): Discourse and Migration. En R. Zapata-Barrero y E. Yalaz (Eds.), Qualitative Research in European Migration Studies (pp. 227-245). Cham, Springer.

EASTON, S. (2018): The politics of the prison and the prisoner: Zoon Politikon. Londres, Routledge.

FILI, A. (2013): Women in Prison: Victim or Resisters? Representations on Agency on women's prisons in Greece. Signs: Women, Gender, and Prison: National and Global Perspectives, 39(1), pp. 1-26. https://www.jstor.org/stable/10.1086/670862

FOUCAULT, M. (1975): Discipline and Punishment. The Birth of the Prison. New York, Vintage Books.

GLASER, B. \& STRAUSS, A. (2017): The Discovery of Grounded Theory: Strategies for qualitative research. Londres, Routledge.

GOFFMAN, E. (1961): Asylums: Essays on the Social Situation of Mental Patients and Other Inmates. New York, Doubleday.

GREER, C. \& REINER, R. (2012): Mediated mayhem: media, crime, criminal justice. En M. Maguire, R. Morgan y R. Reiner (Eds.), The Oxford Handbook of Criminology (5ta edición, pp. 245-278). Oxford, Oxford University Press.

GUALA, N. (2016): La corrección de las mujeres: del reformatorio religioso a la prisión contemporánea. Un estudio de caso. Delito y Sociedad: revista de Ciencias Sociales, (42), pp. 49-74.

INSTITUTO DE ESTUDIOS PERUANOS (marzo 2019): Informe de Opinión Especial sobre seguridad ciudadana. Encuesta nacional urbano rural. IEP. https://iep.org.pe/wpcontent/uploads/2019/03/Informe-OP-Marzo-2019-7-Seguridad-ciudadana-3.pdf 
INSTITUTO NACIONAL DE ESTADÍSTICA E INFORMÁTICA (2020): Estadísticas de las Tecnologías de Información y Comunicación en los Hogares. INEI https://www.inei.gob.pe/media/MenuRecursivo/boletines/boletin tics.pdf

INSTITUTO NACIONAL PENITENCIARIO DEL PERÚ (19 de abril 2020): En el E.P. Pampas de Sananguillo se realizó la tercera campaña general de limpieza como medida preventiva permanente contra el \#COVD19 [Página de Facebook]. Facebook. https://www.facebook.com/INPEGOB/photos/a.2274245722800919/3188753071350175 (2020): Informe estadístico penitenciario marzo 2020. Lima, INPE.

JEWKES, Y. (2002): The Use of Media in Constructing Identities in the Masculine Environment of Men's Prisons. European Journal of Communication, 17(2), pp. 205-225. https://doi.org/10.1177/0267323102017002693

KIDD-HEWITT, D. (1995): Crime and the media: a criminological perspective. En D. KiddHewitt y R. Osborne (Eds.), From Crime and the Media: The Post-Modern Spectacle (pp. 924). Londres, Pluto Press.

KLANDERMANS, B. (2017): Promoting or Preventing Change Through Political Participation. En M. Van Zomeren y J. F. Dovidio (Eds.), The Oxford Handbook of the Human Essence (pp. 207-218). Oxford, Oxford University Press.

LOFARO, R. J. \& MCCUE, C. (2020): Salient target populations and the subcategorization of deviants in the release of inmates during the COVID-19 pandemic. Administrative Theory \& Praxis, 42(3), pp. 379-393. https://doi.org/10.1080/10841806.2020.1794745

MATHIESEN, T. (1997): The viewer society. Michel Foucault's 'Panopticon' revisited. Theoretical Criminology, 1(2), pp. 215-234. https://doi.org/10.1177/1362480697001002003

MEDIA OWNERSHIP MONITOR PERÚ (2020): Impresos. MOM Perú. https://peru.momrsf.org/es/medios/prensa 
MELOSSI, D. \& PAVARINI, M. (2017): Cárcel y Fábrica. Los orígenes del sistema penitenciario (Siglos XVI-XIX). Buenos Aires, Siglo XXI Editores.

MENGO, R. I. (2004): El discurso como acción social. Revista Latina de Comunicación Social, 7(58), pp. 1-7. Recuperado de https://www.redalyc.org/pdf/819/81975811.pdf

MINISTERIO DE JUSTICIA Y DERECHOS HUMANOS (25 de junio 2020): Las 20 acciones del MINJUSDH durante los 100 días de la Emergencia Nacional. gob.pe. Plataforma digital única del Estado Peruano. https://www.gob.pe/institucion/minjus/noticias/188435-las20-acciones-del-minjusdh-durante-los-100-dias-de-la-emergencia-nacional

MORENO, H. (2016): La deformación mediática de los jóvenes pandilleros. Revista Nuestramérica, 4(8), pp. 81-100. http://www.redalyc.org/articulo.oa?id=551957377008

NOWONTY, K. M. \& PIQUERO, A. R. (2020): The global impact of the pandemic on institutional and community corrections: Assessing short-term crisis management and longterm change strategies. Victims \& offenders. 15(1), pp. 1-9.

https://doi.org/10.1080/15564886.2020.1813229

PÁRAMO, D. (2015): La teoría fundamentada (Grounded Theory), metodología cualitativa de investigación científica. Pensamiento \& Gestión, (39), pp. 1-7. http://www.scielo.org.co/scielo.php?script=sci arttext\&pid=S1657$\underline{62762015000200001 \& \operatorname{lng}=\mathrm{en} \& \mathrm{t} \operatorname{lng}=\mathrm{pt}}$

PARDO, N. G. (2007): Cómo hacer análisis crítico del discurso. Una perspectiva latinoamericana. Santiago, Frasis.

PÉREZ-CORREA, C. (2013): Marcando al delincuente: estigmatización, castigo y cumplimiento del derecho. Revista Mexicana de Sociología, 75(2), pp. 287-311. http://www.scielo.org.mx/pdf/rms/v75n2/v75n2a5.pdf

PYROOZ, D., LABRECQUE, R., TOSTLEBE, J. \& USEEM, B. (2020): Views on COVID-19 from Inside Prison: Perspectives of High-security Prisoners. Justice Evaluation Journal, 3(2), pp. 294-306. http://dx.doi.org/10.1080/24751979.2020.1777578 
REDACCIÓN MANO ALZADA (2020): Internas de Chorrillos piden libertad para procesadas, adultas mayores y enfermas crónicas. Mano Alzada.

https://manoalzada.pe/feminismos/internas-de-chorrillos-piden-libertad-paraprocesadas-adultas-mayores-y-enfermas-cronicas

RENZETTI, C. (2018): Feminist Criminology. En W. Dekeseredy y M. Dragiewicz (Eds.), Routledge Handbook of Critical Criminology (2nd ed., pp. 74-82).

https://dx.doi.org/10.4324/9781315622040-7

SCHLESINGER, P., TUMBER, H. \& MURDOCK, G. (1991): The Media Politics of Crime and Criminal Justice. The British Journal of Sociology, 42(3), pp. 397-420.

https://doi.org/10.2307/591187

STRAUSS, A. \& CORBIN, J. (2002): Bases de la investigación cualitativa. Técnicas y procedimientos para desarrollar la teoría fundamentada. Medellín, Editorial Universidad de Antioquía.

USEEM, B. \& KIMBALL, P. (1991): States of Siege: US Prison Riots, 1971-1986. Oxford, University Press.

USEEM, B. (2018): Prison Riots. The Oxford Handbook of Prisons and Imprisonment. Oxford Handbooks Online. DOI: 10.1093/oxfordhb/9780199948154.013.13

VARONA, D. (2011): Medios de comunicación y punitivismo. InDret: Revista para el Análisis del Derecho, (1), pp. 6-35.

https://dialnet.unirioja.es/servlet/articulo?codigo $=3888867$

VEEKEN, H. (2000): Lurigancho prison: Lima's 'high school' for criminality. British Medical Journal, 320, pp. 173-175. https://doi.org/10.1136/bmj.320.7228.173 